\title{
What is the UK Public Searching for? A Correlation Analysis of Google Trends Search Terms and Cosmetic Surgery in the UK
}

\author{
${\mathrm{Zoe} \mathrm{Li}^{1,2} \text { (1) George Filobbos }}^{1}$
}

Received: 23 May 2020/Accepted: 5 August 2020/Published online: 25 August 2020

(C) Springer Science+Business Media, LLC, part of Springer Nature and International Society of Aesthetic Plastic Surgery 2020

\begin{abstract}
Introduction Search engine optimisation (SEO) in plastic surgery practice is crucial for increasing web traffic. Knowing what patients are searching for online can help plastic surgeons understand public interest, enhance patient engagement, and improve service provision. This study analyses the correlation between Google Trends (GT) search activity and the number of cosmetic procedures carried out in the UK.

Methods GT search term data were analysed for popularity of use and geographical variation in the UK. Pearson's correlation coefficient was used to analyse GT data against the number of cosmetic surgery procedures undertaken in the UK in the corresponding year and with 1-year time lag. Results GT score was higher for most colloquial search terms, such as "tummy tuck" compared to "abdominoplasty" (GT score 59 vs 6), but "otoplasty" was higher than "ear correction" (GT score 55 vs 19). Geographical variation showed that London ranked first in proportional search term activity for "brow lift" and Birmingham for "tummy tuck". There was statistically significant positive correlation for three search terms and the number of corresponding surgeries undertaken. This increased to nine search terms when analysed with a 1-year time lag.
\end{abstract}

Zoe Li

zoeli@ doctors.org.uk

1 Department of Plastic Surgery, University Hospitals Birmingham NHS Foundation Trust, Mindelsohn Way, Birmingham B15 2TH, UK

2 The Welsh Centre for Burns and Plastic Surgery, Morriston Hospital, Heol Maes Eglwys, Morriston, Cwmrhydyceirw, Swansea SA6 6NL, UK
Conclusion These results highlight the trends in online search activity in the UK and their correlation with cosmetic procedures. The higher number of significant correlations with 1-year time lag may reflect the patient's decision-making journey to undergo cosmetic surgery. These results can be utilised for SEO, thus leading to a better-informed public and more robust practice building. Level of Evidence $V$ This journal requires that authors assign a level of evidence to each article. For a full description of these Evidence-Based Medicine ratings, please refer to the Table of Contents or the online Instructions to Authors www.springer.com/00266.

Keywords Plastic surgery $\cdot$ Cosmetic surgery $\cdot$ Search engine optimisation - Google trends - Search trends - Web page design

\section{Introduction}

Almost every visit to a plastic surgeon is preceded by an online search. Studies looking at patient behaviour found that over $70 \%$ of patients search for information on the internet prior to their first cosmetic surgery consultation [1-3]. The UK ranked third in the EU for internet use in 2018 [4]. Search term analytic data have been used extensively by many product and market research teams, as well as in politics and health care [5-9]. In plastic surgery, studies have been utilising search term analytic tools such as Google Trends (GT) to characterise interest in procedures, ranging from Mohs micrographic surgery to breast reconstruction [10-15]. Knowing what patients are searching for online can help plastic surgeons understand public interest, enhance patient engagement, and improve service provision. Practically, these objectives can be 
achieved by aiding surgeons in web page design with search engine optimisation (SEO). Even though the UK cosmetic surgery market is estimated to be worth $£ 3.6$ billion [16], there are no studies published to date on GT data and cosmetic plastic surgery in the UK.

The aim of this work is to study the correlation between GT search term activity and cosmetic procedures carried out in the UK. To the best of our knowledge, this is the first study of this type in the UK.

\section{Materials and Methods}

The number of cosmetic surgery procedures carried out annually in the UK was sourced from the published annual audit results of the British Association of Aesthetic Plastic Surgeons (BAAPS) [17]. Data were available for the period 2009-2018 for the top ten most frequently undertaken procedures. The numbers for fat transfer procedures were only available between 2011 and 2018. For all included procedures, a variety of search terms were generated based on researcher consensus and from examples highlighted as showing positive correlation in the US studies [12, 18]. These terms included the medical names of procedures (e.g. breast augmentation) and their colloquial alternatives (e.g. boob job). These were selected as they were likely search terms used by patients (Table 1). Facelift and neck lift surgeries were excluded from the analysis as BAAPS only published a combined procedural volume for these surgeries, which would have been difficult to analyse for correlation with individual search terms of "facelift" and "neck lift".

Using Google Trends "search term" feature, each term was entered individually with the customisation of geographical location set to UK, and time set to the period between 01 January 2009 and 31 December 2018. Google Trends assigns scores between 0 and 100 for each search term over a series of time points, representing the level of search term activity in Google searches. A GT comparison tool allows analysis of different search terms simultaneously over the same time period and geographical location. The scores demonstrate search interest relative to the highest point on the comparison chart for the given region and time. A value of 100 is the peak popularity for the term over the reference time period selected. A value of 50 means that the term is half as popular.

We analysed a comparison of colloquial and medical term search interest for several cosmetic surgery procedures: breast augmentation, abdominoplasty, rhinoplasty, blepharoplasty, and otoplasty. These were selected because they have colloquial equivalents in addition to the medical
Table 1 Search terms used for GT analysis

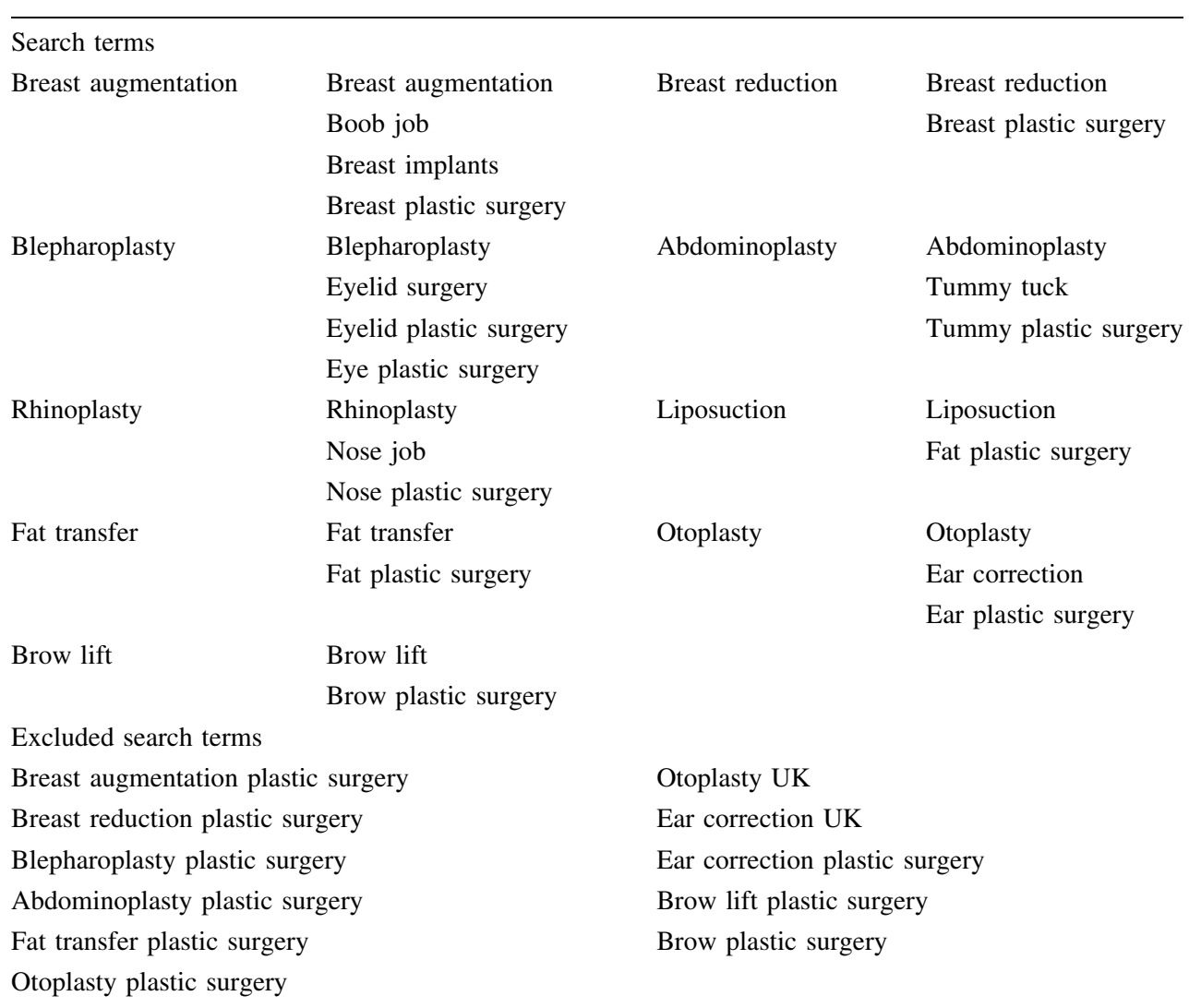


nomenclature. Search terms were also analysed according to geographical locations.

For correlation analysis between GT search terms and the number of cosmetic surgery procedures undertaken in the UK, 25 search terms were included in the study (Table 1). We also added modifier words to achieve more specific characterisation of the search [18]. Modifier words of "surgery", "UK", and "plastic surgery" were added to each search term individually where possible to generate separate GT databases. Our aim was to identify search activity for users specifically interested in having their surgery in the UK. Eleven of the modified search terms had to be excluded due to insufficient search volume data on GT.

Mean search activity values were calculated per year, and Pearson's correlation coefficient was used to study correlation with the number of corresponding surgeries undertaken that year. Results that showed moderate or strong positive correlation were tested for significance with $p$ value $<0.05$.

A lag correlation of 1 year was also studied for all search terms used, in which mean search activity levels for each year were tested for correlation with the number of corresponding procedures carried out the following year, to investigate the hypothesis that there may be significant time delay between user search activity and surgeries. Mean search activity values for 2009-2017 were analysed with the number of procedures undertaken between 2010 and 2018 using Pearson's correlation coefficient. Results that showed moderate or strong positive correlation were tested for statistical significance with $p$ value $<0.05$.

\section{Results}

\section{Popularity of Search Terms}

GT search interest scores were assessed for the 10-year study period, between 2009 and 2018. Mean scores for each search term were calculated. The search term "boob job" had a much higher mean GT search interest score compared to "breast implants" and "breast augmentation" (GT score of 45 vs 29 and 15, respectively) (Table 2, Fig. 1). The search term "tummy tuck" had a higher GT score compared to "abdominoplasty" (62 vs 7). The search term "nose job" had a higher GT score compared to "rhinoplasty" (58 vs 29). "Eyelid surgery" had a similar GT score to "blepharoplasty" (53 vs 47), whilst "otoplasty" had a higher GT score than "ear correction" (55 vs 19).

\section{Geographical Variation}

GT can determine the city or village where the search term was most popular during the study period. Search popularity is calculated as a fraction of total searches in that location. A higher value means a higher proportion of all queries, not a higher absolute query. Based on this approach, London ranked first in search terms "eyelid surgery", "fat transfer", "otoplasty", and "brow lift" (Table 3). Birmingham ranked first in "tummy tuck". Glasgow ranked first in "breast reduction", Liverpool in "nose job". Nazeing (a village and parish in Essex) ranked first in "boob job". Halesowen ranked first in "liposuction".

\section{Correlation Between Google Trends Search Activity and BAAPS Procedures}

Statistically significant positive correlation was found for three search terms and their corresponding surgeries in the same year. These were "breast plastic surgery" for breast augmentation ( $R=0.659, p=0.038)$, "tummy tuck plastic surgery" for abdominoplasty $(R=0.713, p=0.020)$, and "nose job plastic surgery" for rhinoplasty $(R=0.635$, $p=0.048$ ). There was no statistically significant positive correlation seen with any of the other terms.

\section{One-Year Lag Correlation Between Google Trends Search Activity and BAAPS Procedures}

There was statistically significant positive correlation for nine search terms with the number of corresponding procedures the following year. The term "breast plastic surgery" showed a positive correlation with breast augmentation $(R=0.823, p=0.006)$ and breast reduction $(R=0.811, p=0.007)$. The term "fat plastic surgery" showed a positive correlation with liposuction $(R=0.738$, $p=0.023)$ and fat transfer $(R=0.844, p=0.0169)$. Other search terms showing statistically significant positive correlation were "breast implants plastic surgery" $(R=0.742$, $p=0.021)$ and "boob job plastic surgery" $(R=0.902$, $p=0.0009$ ) for breast augmentation, "eye plastic surgery" $(R=0.712, p=0.031)$ for blepharoplasty, "nose job plastic surgery" $(R=0.815, p=0.007)$ for rhinoplasty, "otoplasty surgery" $(R=0.717, p=0.029)$, "ear correction" $(R=0.718, p=0.029)$, and "ear correction surgery" ( $R=0.670, p=0.048)$ for otoplasty. Figure 2 illustrates the correlations for the annual number of breast augmentation procedures undertaken and the GT scores for the search term "boob job plastic surgery" analysed against the corresponding year $(R=0.596, p=0.069)$ and with 1 -year time lag $(R=0.902, p=0.0009)$. 
Table 2 Mean GT search interest scores for listed search terms, 2009-2018

\begin{tabular}{lll}
\hline Topic & Search term & Mean GT search interest score \\
\hline Breast augmentation & Boob job & 45 \\
& Breast implants & 29 \\
& Breast augmentation & 15 \\
Abdominoplasty & Tummy tuck & 62 \\
Rhinoplasty & Abdominoplasty & 7 \\
& Nose job & 58 \\
Blepharoplasty & Rhinoplasty & 29 \\
& Eyelid surgery & 53 \\
Otoplasty & Blepharoplasty & 47 \\
& Otoplasty & 55 \\
& Ear correction & 19
\end{tabular}

- boob job - breast implants - breast augmentation

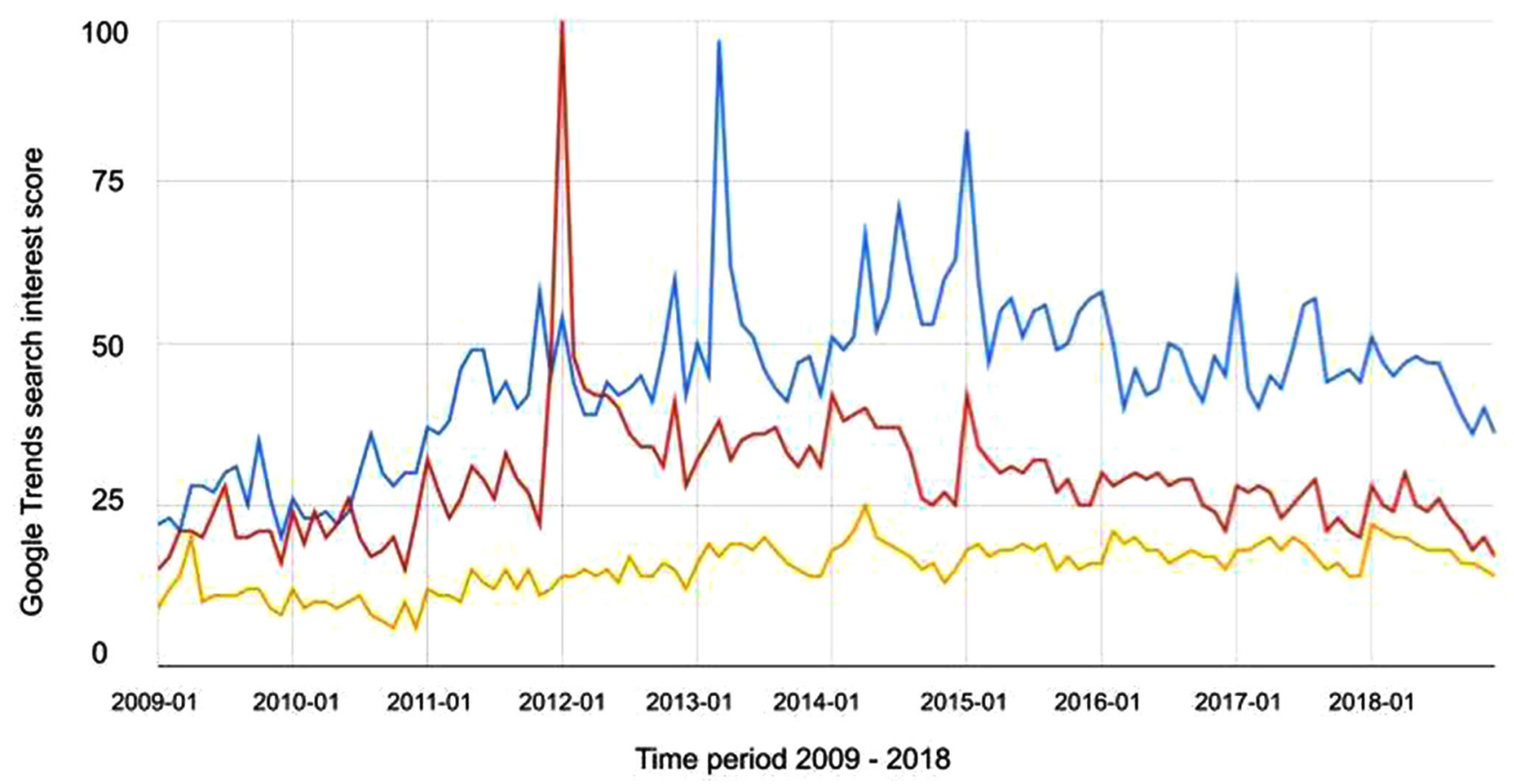

Fig. 1 Popularity comparison of search terms relating to breast augmentation, 2009-2018

\section{Discussion}

The published medical literature on search term analytics has predominantly been using Google Trends (GT). It has proved advantageous compared to other software as it is open source, user friendly, and, most importantly, relevant. It is the most widely used search engine worldwide [19]. Studies utilising GT to look at interest in cosmetic surgery have mostly been US based, and they have identified multiple search terms that demonstrate correlation between search term activity and uptake of their corresponding procedures, such as "breast augmentation", "lip fillers", and "chin implants" [12-14, 18]. These studies have shown validity of the use of GT, but importantly they highlight the need for careful search term selection and reveal geographical differences in search term use.

In our study, the colloquial term "boob job" was more significant of a search term compared to the medical term "breast augmentation". The same applied to "tummy tuck" versus "abdominoplasty". This reflects how the British public more commonly refer to those procedures as "boob jobs" and "tummy tucks". Wilson et al. [12] had demonstrated that there are country variations in the search term "boob job" and that the term was less utilised in the 
Table 3 Top three ranked cities with GT search interest scores by subregion

\begin{tabular}{ll}
\hline Search term & Top three ranked cities \\
\hline Boob job & Nazeing \\
& Liverpool \\
& Portsmouth \\
Breast reduction & Glasgow \\
& Edinburgh \\
Eyelid surgery & Liverpool \\
Tummy tuck & London* \\
& Birmingham \\
& Leeds \\
Nose job & Liverpool \\
& Liverpool \\
Liposuction & Halesowen \\
& Brighton \\
Fat transfer & Halesowen \\
Otoplasty & Croydon \\
Brow lift & Nazeing \\
\hline
\end{tabular}

*No other cities listed in the results

United States compared to Ireland, Australia, or the UK. This study highlights the more commonly used search terms in the UK and can thus guide plastic surgeons and web page designers to accentuate the terms the public is searching for. Whilst colloquial search terms were more common in the case of "boob job" and "tummy tuck", "otoplasty" was the more common search term. This demonstrates that the use of colloquial terms is not always the rule for search terms in cosmetic surgery in the UK. The plastic surgeon and web page designer need to adjust to the demands of the public in providing information and guiding traffic towards their websites.

Our study also analysed the geographical variation in search term usage. We believe this to be crucial for any private cosmetic surgery practice. Plastic surgeons can utilise these data to adjust their services and websites in accordance with what the public is looking for in their area of practice. This can also guide further training and skill acquisition for plastic surgeons so that their skill set can meet the cosmetic surgery requirements of their local population. It was interesting to find out that in the UK, the small village and parish of Nazeing (with a population of 4267) had the highest fraction out of total searches for "boob job" in the country.

In this study, there was generally a positive correlation between the frequency of search terms and the number of cosmetic procedures. This correlation was only statistically significant for three terms (out of 25) in the same year. This increased to nine search terms using 1-year lag correlation. Figure 2 illustrates the strong positive correlation between breast augmentation procedures and the search term "boob job plastic surgery" when analysed with a 1-year time lag, compared to analysis against the corresponding year where the correlation was not statistically significant. This could indicate that the public needs time between conducting the online search and having the procedure. Haas et al. [20] discuss the motivating factors for seeking cosmetic surgery

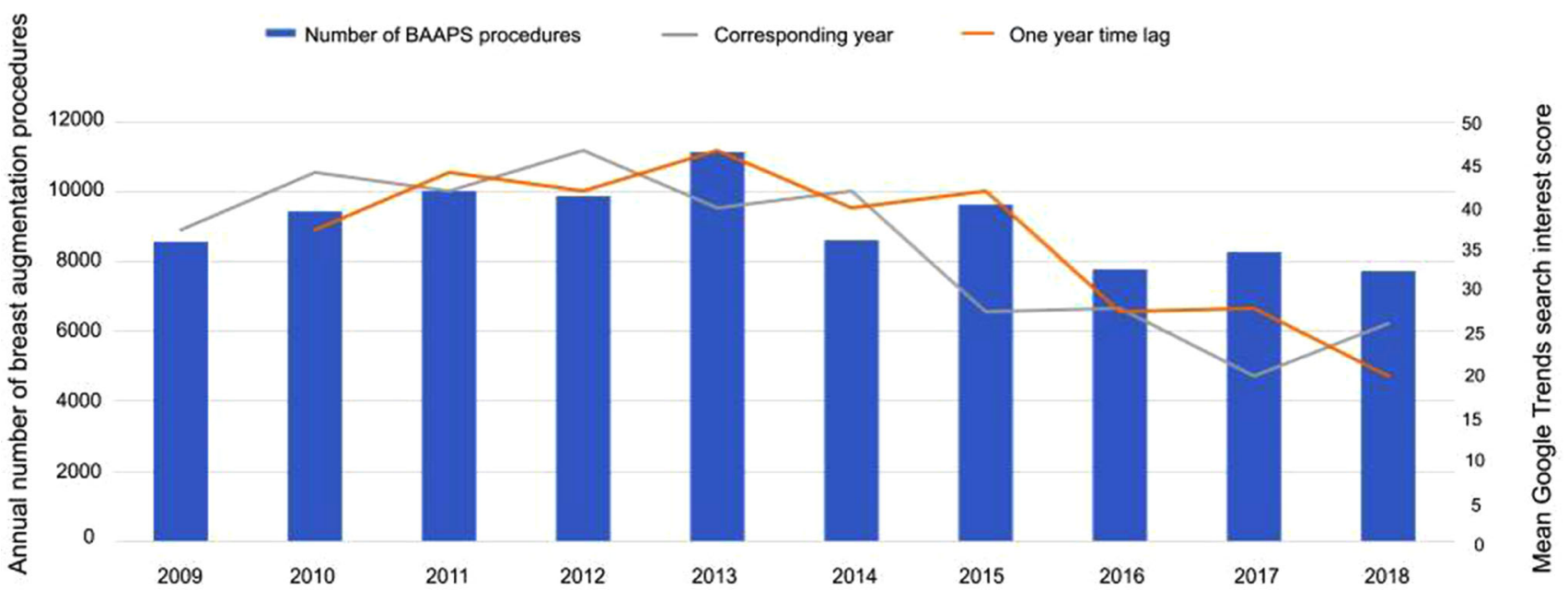

Year

Fig. 2 The annual number of breast augmentation procedures and mean GT scores for search term "boob job plastic surgery" in the corresponding year and with 1-year time lag. The orange line shows statistically significant positive correlation with 1-year time lag ( $R=0.902, p=0.0009)$ unlike the correlation with the corresponding year as depicted by the grey line $(R=0.596, p=0.069)$ 
and highlight the emotional and psychological motivation along with the socio-economic aspect. This decisionmaking journey to undergo cosmetic surgery takes time, and we believe this is reflected in the higher number of significant correlations after 1 year. This 1-year correlation lag allows the plastic surgeon and web page designers the time to adjust their websites to better inform patients based on the search results a year earlier.

\section{Search Engine Optimisation (SEO)}

SEO is the process of increasing website traffic in terms of both quality and quantity by increasing the visibility of a website on a search engine. SEO specifically refers to improvement of what is known as "natural" or "organic" results which are unpaid results. Rayess et al. [21] studied SEO in rhinoplasty websites. They state that most patients only analyse the results of the first ten websites retrieved. Our aim as plastic surgeons is to empower the public by providing them with high-quality information from well-trained and approved surgeons. We believe that the findings of this study can help plastic surgeons in the UK and their web page designers with SEO. The cost of paid traffic to a website can be quite high, and this would be more of a challenge in the post-COVID 19 world. Therefore, having an increase in "natural or organic" results based on the findings of this paper would provide a cost-effective approach to increasing website traffic. None of the leading search engines (including Google) fully disclose their algorithms for ranking web pages. However, search terms and geographical variation have an impact on this ranking [22]. Our study offers useful information on both aspects and can therefore help with SEO.

It would be interesting to investigate search term trends for cosmetic surgery in other countries using their native languages. Bousquet et al. [23] demonstrate that GT terms on rhinitis differ across European countries. These studies rely on researcher insight into colloquial terminology in addition to the use of medical nomenclature. Plastic surgeons in other countries could utilise local insights to adjust to the needs of their patients.

In our current time, websites are competing for web traffic. Camp et al. [24] highlight the risk that plastic surgeons are losing the online competition to non-physicians with increasingly sophisticated websites and listing services being set up by independent parties. We hope this study serves as a reminder to the importance of keeping up with the times both for better patient information and for more robust practice building.

\section{Limitations}

We acknowledge that this study only utilised data available from BAAPS. There are other cosmetic surgery procedures performed by surgeons and independent parties without being part of BAAPS or BAPRAS (British Association of Plastic, Reconstructive and Aesthetic Surgeons). It was not possible to acquire these numbers as they are not nationally audited. We recommend that patients have their procedures with well-trained and approved surgeons.

\section{Conclusion}

Even though the UK cosmetic surgery market is estimated to be worth $£ 3.6$ billion, this is the first published study on GT data and cosmetic plastic surgery in the UK. The results of this study highlight the search trends in the UK and their correlation with cosmetic procedures. These results can be utilised for SEO, thus leading to a betterinformed public and more robust practice building.

\section{Compliance with Ethical Standards}

Conflict of interest The authors declare that they have no conflict of interest.

Human and Animal Rights This article does not contain any studies with human participants or animals performed by any of the authors.

Informed Consent For this type of study, informed consent is not required.

\section{References}

1. Montemurro P, Porcnik A, Hedén P, Otte M (2015) The influence of social media and easily accessible online information on the aesthetic plastic surgery practice: literature review and our own experience. Aesthet Plast Surg 39(2):270-277

2. Nassab R, Hamnett N, Nelson K, Kaur S, Greensill B, Dhital S, Juma A (2010) Cosmetic tourism: public opinion and analysis of information and content available on the Internet. Aesthet Surg J 30(3):465-469

3. Walden JL, Panagopoulous G, Shrader SW (2010) Contemporary decision making and perception in patients undergoing cosmetic breast augmentation. Aesthet Surg J 30(3):395-403

4. Office for National Statistics (2019) Internet users, UK: 2019 statistical bulletin [Internet]. Available from https://www.ons. gov.uk/businessindustryandtrade/itandinternetindustry/bulletins/ internetusers/2019. Accessed 10 Feb 2020

5. Choi H, Varian H (2009) Predicting the present with Google trends [Internet]. Official Google Research Blog. Available from https://static.googleusercontent.com/media/www.google.com/ en//googleblogs/pdfs/google_predicting_the_present.pdf. Accessed 10 Feb 2020

6. Reilly S, Richey S, Taylor JB (2012) Using Google search data for state politics research: an empirical validity test using roll-off data. State Polit Policy Q 12(2):146-159

7. Verma M, Kishore K, Kumar M, Sondh AR, Aggarwal G, Kathirvel S (2018) Google search trends predicting disease outbreaks: an analysis from India. Healthc Inform Res 24(4):300

8. Nuti SV, Wayda B, Ranasinghe I, Wang S, Dreyer RP, Chen SI, Murugiah K (2014) The use of Google trends in health care research: a systematic review. PLoS ONE 9(10):e109583 
9. Rahiri J-L, Barazanchi A, Furukawa S, MacCormick AD, Harwood M, Hill AG (2018) Using Google trends to explore the New Zealand public's interest in bariatric surgery: Google trends and bariatric surgery. ANZ J Surg 88(12):1274-1278

10. Callaghan DJ (2018) Use of Google trends to examine interest in Mohs micrographic surgery: 2004 to 2016. Dermatol Surg 44(2):186-192

11. Ward B, Ward M, Paskhover B (2018) Google trends as a resource for informing plastic surgery marketing decisions. Aesthet Plast Surg 42(2):598-602

12. Wilson SC, Daar DA, Sinno S, Levine SM (2018) Public interest in breast augmentation: analysis and implications of Google trends data. Aesthet Plast Surg 42(3):648-655

13. Tijerina JD, Morrison SD, Nolan IT, Vail DG, Lee GK, Nazerali R (2020) Analysis and interpretation of Google trends data on public interest in cosmetic body procedures. Aesthet Surg J 40(1):NP34-NP43

14. Motosko CC, Zakhem GA, Saadeh PB, Hazen A (2018) Googling aesthetic plastic surgery for patient insights into the latest trends. Plast Reconstr Surg 142(6):1478-1485

15. Whipple LA, Kotamarti VS, Heiman AJ, Patel A, Ricci JA (2019) Using Google trends to analyze patient search interest in implantbased and autologous breast reconstruction. Breast J. https://doi. org/10.1111/tbj.13675

16. Buisson L (2019) Cosmetic surgery UK market report. First edition. Published 5th September 2019

17. The British Association of Aesthetic Plastic Surgeons. BAAPS annual audit results [Internet]. Available from https://baaps.org. uk/baaps_annual_audit_results_.aspx. Accessed 10 Feb 2020
18. Tijerina JD, Morrison SD, Nolan IT, Vail DG, Nazerali R, Lee GK (2019) Google trends as a tool for evaluating public interest in facial cosmetic procedures. Aesthet Surg J 39(8):908-918

19. Search Engine Market Share Worldwide [Internet]. StatCounter Global Stats. Available from https://gs.statcounter.com/searchengine-market-share. Accessed $10 \mathrm{Feb} 2020$

20. Haas CF, Champion A, Secor D (2008) Motivating factors for seeking cosmetic surgery: a synthesis of the literature. Plast Surg Nurs 28(4):177-182

21. Rayess H, Gupta A, Nissan M, Carron M, Zuliani G (2017) Search engine optimization: an analysis of rhinoplasty web sites. Facial Plast Surg 33(06):665-669

22. Strzelecki A (2020) Google medical update: why is the search engine decreasing visibility of health and medical information websites? Int J Environ Res Public Health [Internet] 17(4)

23. Bousquet J, Agache I, Anto JM, Bergmann KC, Bachert C, Annesi-Maesano I et al (2017) Google trends terms reporting rhinitis and related topics differ in European countries. Allergy 72(8):1261-1266

24. Camp MC, Wong WW, Mussman JL, Gupta SC (2010) The battle for hearts and minds: who is communicating most effectively with the cosmetic marketplace? Aesthet Surg J 30(4):614-617

Publisher's Note Springer Nature remains neutral with regard to jurisdictional claims in published maps and institutional affiliations. 